\title{
Influence of alkali and acidic treatment on sorption properties of Latvian illite clays
}

\author{
Vitālijs Lakevičs ${ }^{1, a}$, Valentīna Stepanova², leva Skuja ${ }^{3}$, Inga Dušenkova ${ }^{4}$ \\ and Augusts Ruplis ${ }^{5}$ \\ ${ }^{1-5}$ Institute of General Chemical Engineering, Riga Technical University, Azenes 14/24, \\ LV-1048, Riga, Latvia \\ a vitalijs.lakevics@rtu.Iv
}

Keywords: adsorption, Latvian clays, illite, specific surface, acidic treatment, alkali

\begin{abstract}
The adsorption of monovalent organic cationic methylene blue dye on natural and modified with hydrochloric acid and sodium hydroxide Latvian clay samples from water solutions has been studied. It was established that alkali and acidic treatment of Latvian clay samples changes their sorption characteristics. It was found that increasing concentration of hydrochloric acid from 5 mass \% up to 15 mass \% decreases adsorption of clay samples proportionally to the acid concentration. Increasing concentration of sodium hydroxide from 5 mass $\%$ to 15 mass $\%$, BET specific surface area of the modified clay samples is smaller than BET specific surface area of the natural clay sample. The studies have proven that adsorption ability of Latvian clays is sufficient for using them in waste water purification from admixtures of organic dyes.
\end{abstract}

\section{Introduction}

Latvian illite containing clays, due to their wide distribution, physical-chemical and colloidal properties, have potential application as low-cost and eco-friendly adsorbents for industrial waste purification from organic dyes [1], for discoloration of rapeseed oil [2], petroleum, oil [3] and heavy metals [4]. The increasing interest towards modified clays is explained by necessity to create environmentally safe sorbents. Clays can be modified with inorganic acids and metal salts, which are part of the clay [5], alkali [6], etc. The aim of this work is to study sorption properties of natural and modified Latvian illite clay samples depending on alkali and acidic treatment conditions.

\section{Materials and Methods}

Materials. Latvian illite containing clay samples from Tūja (Devonian), Laža (Quaternary) and Strēḷi (Jurassic) deposits were studied. Non-modified clay samples were taken from deposits, mechanically cleared from additions, crashed in a pestle, dispersed and swollen in distilled water for 1 month. Swollen clay samples were fractionated by wet sieving through 230 mesh $(63 \mu \mathrm{m})$ sieve and dried in $105^{\circ} \mathrm{C}$ temperature. The acidic modified clay samples were prepared from natural clay samples by hydrochloric acid treatment in a glass bulb provided with a cooling pipe on water bath at $95^{\circ} \mathrm{C}$ for four hours, similar to shown in [7]. The ratio of acid to clay mass was 10:1. After acidic treatment, the samples were washed in distilled water by decantation until $\mathrm{pH} 3-4$ then dried at room temperature. The samples were obtained by using 5, 10 and 15 mass $\%$ of hydrochloric acid solutions. The alkali modified clay samples were also prepared from natural clay samples by sodium hydroxide treatment in a glass bulb provided with a cooling pipe on water bath at $80^{\circ} \mathrm{C}$ for one hour, following the methodology described in the source [8]. Alkali to clay mass ratio was 10:1. After alkali treatment, the samples were washed in distilled water by decantation until $\mathrm{pH} \mathrm{7,} \mathrm{and}$ then dried at room temperature.

Sample Characterization. Mineralogical composition of obtained clay samples was analyzed by Xray powder diffraction (XRD) (X'Pert Pro, Philips, The Netherlands). Elemental characterization of the natural and modified clay samples were analyzed by energy-dispersive X-ray spectroscopy 
(EDX) (Inca Energy 350, Oxford Instruments). Specific surface area of the samples was measured using the BET method utilizing adsorption of $\mathrm{N}_{2}$ gas (purity $99.99 \%$ ) at $77 \mathrm{~K}$ (Quadrasorb SIKR/MP, Quantachrome Instruments, USA). For this purpose, $0.02-0.30 \mathrm{~g}$ of the composition samples were outgassed for $4 \mathrm{~h}$ at $200^{\circ} \mathrm{C}$.

Adsorption of methylene blue. $0,5 \mathrm{~g}$ dried clay sample was added to $50 \mathrm{ml}$ of aqueous solution of methylene blue with initial concentration $2 \mathrm{~g} / \mathrm{l}$ and then shaken in Biosan Multi-Shaker PSU 20 shaker type. It was established that the concentration became constant after $24-30$ hours of shaking. $10 \mathrm{ml}$ of the equilibrated solution was separated from the clay by centrifugation (4 minutes at $6500 \mathrm{rpm}$ ). The concentration of methylene blue from water solutions was determined using „Jenway 6405 UV/VIS" spectrophotometer, measuring visible spectra at $582 \mathrm{~nm}$ in static conditions at room temperature $\left(\mathrm{t}=20 \pm 1{ }^{0} \mathrm{C}\right)$. The optical densities were converted to concentrations by reference to calibration data. The adsorption experiments were performed in triplicate.

\section{Results and discussion}

Fig. 1. shows the XRD patterns of acidic and alkali modified clay samples from Streli deposit. During the alkali and acidic action on the sample, an important change in the mineralogical composition occurs. The acid treatment leads to severe mineral crystal structure alteration which is shown characteristic peaks lowering on the patterns, indicating a decrease in the regularity of the mineral structure. As it can be seen, the content of calcite and hematite in the clay samples decreases proportionally with increasing of hydrochloric acid concentration, but quartz content is proportionally increased due to loss of hematite mass. Active amorphous silica gel formation occurs. Mineralogical composition of clay samples modified with sodium hydroxide shows that content of calcite, hematite, quartz and illite in the clay samples decreases when sodium hydroxide concentration increases from 5 to 15 mass \%. Similar tendencies were also observed with clay samples from Tūja and Laža deposits.

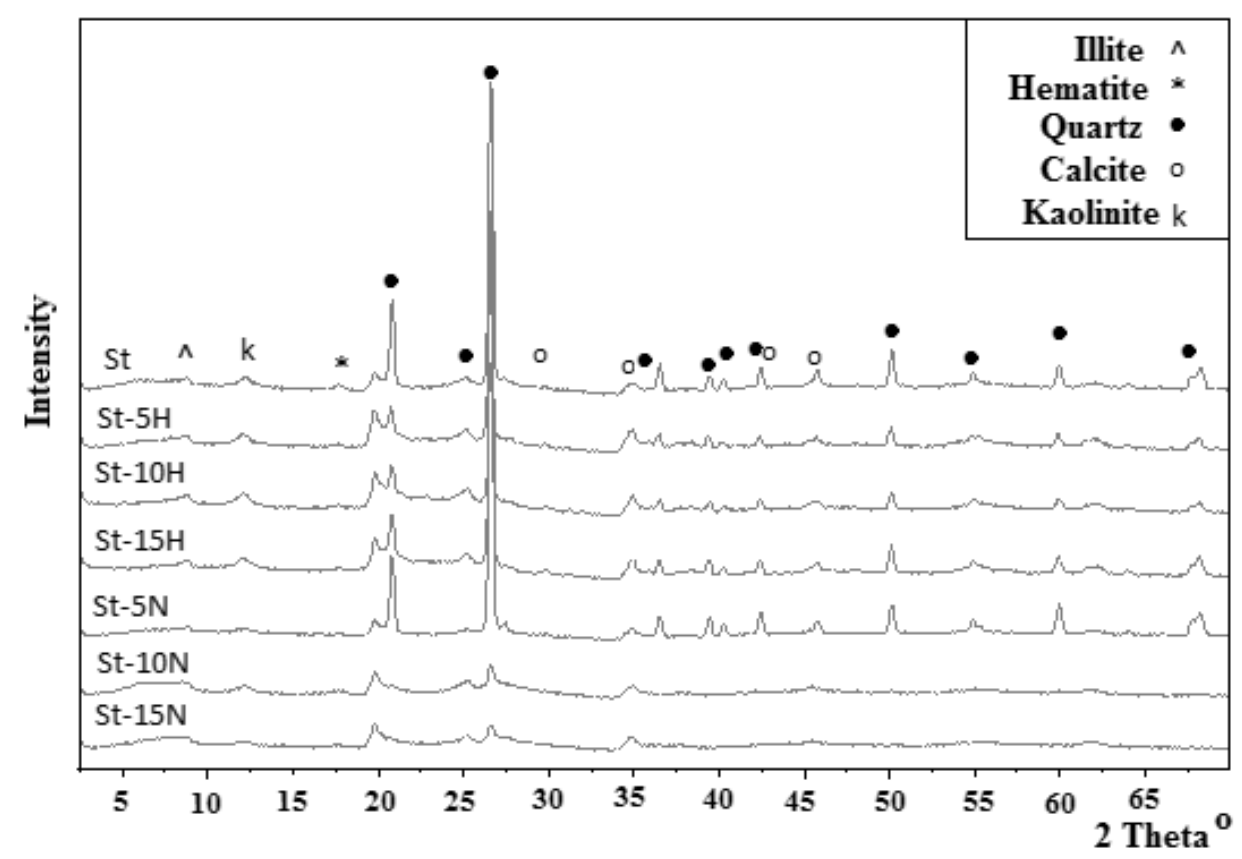

Fig.1 XRD patterns of natural and acidic and alkali modified clay samples from Strel̦i deposit: St non modified clay sample; St-5H; St-10H; St-15H - clay samples, treated with $5 \%, 10 \%$ and $15 \% \mathrm{HCl} ; \mathrm{St}-5 \mathrm{~N} ; \mathrm{St}-10 \mathrm{~N}$; St-15N - clay samples, treated with $5 \%, 10 \%$ and $15 \% \mathrm{NaOH}$.

Elemental characterization of the natural and acidic and alkali modified clay samples is shown in table 1. The content of iron, magnesium, calcium, some silica and alumina decreases in the 
samples treated with $5-15 \% \mathrm{HCl}$. Sodium hydroxide removed some silica from the samples, but was less effective in removing the other constituents than HCI.

Table 1 Elemental characterization of the natural and modified clay samples

\begin{tabular}{|l|c|c|c|c|c|c|c|c|c|c|c|c|}
\hline \multirow{2}{*}{$\begin{array}{c}\text { Sample } \\
\text { code }\end{array}$} & \multicolumn{9}{|c|}{ Mean amount of the elements in natural and modified clay samples, [mass \%] } \\
\cline { 2 - 15 } & $\mathrm{C}$ & $\mathrm{O}$ & $\mathrm{Na}$ & $\mathrm{Mg}$ & $\mathrm{Al}$ & $\mathrm{Si}$ & $\mathrm{K}$ & $\mathrm{Ca}$ & $\mathrm{Ti}$ & $\mathrm{Fe}$ & $\mathrm{Zn}$ & Total \\
\hline St & 6.56 & 58.76 & 0.04 & 1.14 & 9.17 & 20.88 & 1.75 & 0.00 & 0.35 & 1.35 & - & 100.0 \\
\hline St-5N & 9.02 & 53.76 & 0.14 & 1.46 & 9.70 & 20.10 & 1.91 & 0.61 & 0.59 & 2.32 & 0.39 & 100.0 \\
\hline St-10N & 5.71 & 59.49 & 0.46 & 1.36 & 9.73 & 19.66 & 1.62 & 0.49 & 0.30 & 1.20 & - & 100.0 \\
\hline St-15N & 5.48 & 56.73 & 0.66 & 1.59 & 10.02 & 20.63 & 1.94 & 0.64 & 0.47 & 1.85 & - & 100.0 \\
\hline St-5H & 8.72 & 57.22 & - & 0.56 & 3.38 & 29.28 & 0.85 & - & - & 1.20 & - & 100.0 \\
\hline St-10H & 14.51 & 56.86 & - & 0.59 & 6.28 & 19.73 & 0.89 & - & 0.53 & 0.62 & - & 100.0 \\
\hline St-15H & 9.57 & 56.85 & - & 0.21 & 2.36 & 12.87 & 0.25 & - & 17.46 & 0.43 & - & 100.0 \\
\hline
\end{tabular}

Methylene blue adsorption is largely used nowadays as an accurate and efficient procedure for cation exchange capacity (CEC) determination [9]. Fig.2 shows methylene blue adsorption isotherms on natural and acidic and alkali modified Latvian clay samples from Strẹ̄̂i deposit.

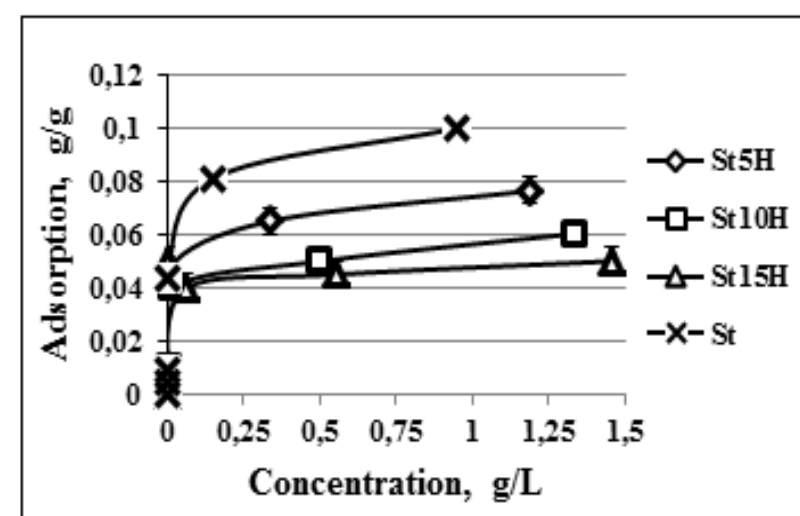

(a)

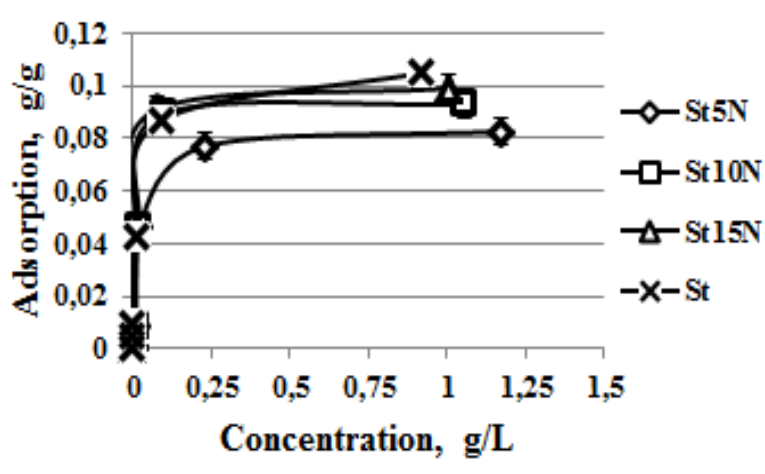

(b)

Fig. 2 Methylene blue adsorption isotherms on acidic (a) and alkali (b) modified Latvian clay samples

The isotherms demonstrate influence of the acid and alkali concentration used for modifying. The values of the CEC estimated from methylene blue adsorption isotherms decreases as the acid concentration increases. The decreases in CEC were correlated with the losses of metals from the lattice, again indicating the decomposition of a part of the clay. The values of CEC increases with the increasing of alkali concentration (see Table 2). The acidic treatment affects surface areas more than the alkaline treatment. The increase of the BET surface area under acid treatment may be caused by production of finely dispersed silicon oxides from destruction of mineral structures, removal of amorphous $\mathrm{Al}$ or silica components plugging surface pores. A large value for the BET surface area is important for catalytic activity of acidic modified clays.

Under alkaline conditions, similar processes may occur together with accumulation of $\mathrm{Fe}$ and $\mathrm{Mg}$ compounds (see Table 1). Similar tendencies were also observed with clay samples from Tūja and Laža deposits. 
Table 2 BET specific surface area and CEC of natural and modified clay samples

\begin{tabular}{|c|c|c|c|c|c|c|}
\hline \multirow{2}{*}{$\begin{array}{c}\text { Sample } \\
\text { code }\end{array}$} & \multicolumn{2}{|c|}{$\begin{array}{c}\text { Modifier } \\
\text { concentration, } \\
{[\mathrm{mass} \%}\end{array}$} & \multicolumn{2}{c|}{$\begin{array}{c}\text { Treatment } \\
\text { conditions }\end{array}$} & $\begin{array}{c}\text { BET specific } \\
\text { surface area, } \\
{\left[\mathrm{m}^{2} / \mathrm{g}\right]}\end{array}$ & $\begin{array}{c}\text { CEC, } \\
{[\mathrm{meq} / 100 \mathrm{~g}]}\end{array}$ \\
\cline { 2 - 5 } & $\mathrm{HCl}$ & $\mathrm{NaOH}$ & $\mathrm{t},\left[{ }^{\circ} \mathrm{C}\right]$ & {$[\mathrm{h}]$} & & \\
\hline St & - & - & - & - & 32,9 & 27,9 \\
\hline St-5H & 5 & - & 95 & 4 & 54,7 & 16,5 \\
\hline St-10H & 10 & - & 95 & 4 & 92,6 & 14,1 \\
\hline St-15H & 15 & - & 95 & 4 & 100,0 & 10,7 \\
\hline St-5N & - & 5 & 80 & 1 & 18,7 & 16,5 \\
\hline St-10N & - & 10 & 80 & 1 & 26,2 & 22,9 \\
\hline St-15N & - & 15 & 80 & 1 & 29,9 & 25,4 \\
\hline
\end{tabular}

\section{Summary}

For the first time, the influence of the acidic and alkali treatment on the sorption properties of the clay samples from Strẹ̄̂i, Tūja and Laža deposits were characterized. Modifying with $\mathrm{NaOH}$ and $\mathrm{HCl}$ solutions changes the adsorption properties of natural clay samples. The acidic treatment affects BET surface area of the investigated samples more than the alkali treatment. The values of the CEC estimated from methylene blue adsorption isotherms decreases as the acid concentration increases. The decreases in CEC were correlated with the losses of metals from the lattice, again indicating the decomposition of a part of the clay.

\section{Acknowledgements}

This work has been supported by the National Research Program of Latvia 2010-2013 "Sustainable use of local resources (underground resources, wood, food and transport) - new products and technologies (NatRes)" within the project V7804.

\section{References}

[1] Y.S. Ho, C.C. Chiang, Y.C. Hsu, Sorption kinetics for dye removal from aqueous solution using activated clay. Separ. Sci. Technol., 36 (11) (2001) 2473 - 2488.

[2] C.O. Frost Ray, X.Yunfei, S. Kokot, Adsorption of hydrocarbons on organo-clays - implications for oil spill remediation. J. Colloid Interf. Sci., 305 (1) (2007) 17-24.

[3] A. Ruplis, J. Freimanis, A. Actiņš, V. Lakevičs, Colloid-chemical properties of Latvian clays. Latvian J. Chem., 2 (2004) $263-269$.

[4] W.A. Carvalho, C. Vignado, J. Fontana, M.B. Riboldi, The removal of heavy metal ions from aqueous effluents by modified clays: retention of Cd (II) and Ni (II) ions. Adsorpt. Sci. Technol., 25 (9) (2007) $673-692$.

[5] M.Pentrák, A.Czímerová, J.Madejová, P.Komadel, Changes in layer charge of clay minerals upon acid treatment as obtained from their interactions with methylene blue. Applied Clay Science, 55 (2012) $100-107$.

[6] K.Elert, E.Sebastian, I.Valverde, C.Rodriguez-Navarro. Alkaline treatment of clay minerals from the Alhambra Formation: Implications for the conservation of earthen architecture. Appl. Clay Sci., 39 (2008) 122 - 132.

[7] A.Ruplis, R.Būmans, I.Martcin, R. Višs, A. Tyumina, Colloid chemistry of Latvian clays. Latvian J.Chem., 5 (1995) $36-42$.

[8] C.A. Okwara, E.C.Osoka, Caustic activation of local clays for palm oil bleaching. J. Eng. Appl. Sci., 1(4) (2006) 526 - 529.

[9] P.Hang, G.W.Brindley, Methylene blue adsorption by clay minerals. Determination of surface areas and cation exchange capacities. Clays and Clay Minerals, 18 (1970) $203-212$. 